\title{
Purificação e Caracterização de Quitosana Comercial.
}

\author{
Roberta Signini e Sérgio P. Campana Filho
}

Resumo: Procedimentos adequados para as purificações de quitosana comercial como cloridrato e na forma neutralizada são descritos. As amostras obtidas apresentam elevado grau de pureza e baixo teor de cinzas conforme verificado através de termogravimetria. As determinações de graus de acetilação por espectroscopia de ressonância magnética nuclear $(\overline{\mathrm{GA}}=23,6 \%)$ e por titulações $(\overline{\mathrm{GA}}=23,0 \%)$ apresentam muito boa concordância. O cloridrato de quitosana é solúvel em água, o que permite determinações de viscosidade intrínseca em solventes aquosos na ausência de excesso de ácido e facilita a comparação de quitosana com outros polieletrólitos quanto a estimativas de rigidez/flexibilidade.

Palavras-chave: Cloridrato de quitosana, purificação, grau de acetilação, viscosidade intrínseca, soluções aquosas sem excesso de ácido, constante de Huggins.

\section{Introdução}

Quitina e quitosana são polissacarídeos de cadeias lineares que contêm proporções variáveis dos carboidratos 2-acetamido-2-deoxi-D-glicopiranose e 2amino-2-deoxi-D-glicopiranose, unidos por ligações glicosídicas $\beta(1 \rightarrow 4)$. Copolímeros em que predominam unidades de 2-amino-2-deoxi-D-glicopiranose, que são solúveis em meios aquosos ácidos mas que são insolúveis em meios neutros e alcalinos, são denominados quitosanas ${ }^{[1]}$.

Para se determinar as características de quitosana visando correlacioná-las às propriedades que possam resultar em aplicações é necessário que o polissacarídeo seja purificado. De fato, no contexto de algumas aplicações de quitosana, tais como em dispositivos para a liberação controlada de drogas, um elevadíssimo grau de pureza é requerido ${ }^{[1,2]}$.

A purificação de quitosanas na forma neutralizada, solúvel em meios de acidez moderada, é bastante prática do ponto de vista do tempo, materiais e equipamentos necessários à sua execução. Porém, a solubilidade restrita das amostras purificadas limita as suas caracterizações a determinadas condições e, de certa forma, dificulta a comparação de quitosana com outros polieletrólitos.

Exemplo dessas dificuldades é a comparação de quitosana com polieletrólitos aniônicos no que diz respeito a comportamentos viscosimétricos. Em geral, os polieletrólitos aniônicos são purificados em suas formas salinas ${ }^{[3]}$, solúveis em solução aquosa $0,1 \mathrm{~mol} / \mathrm{L}$ de $\mathrm{NaCl}$, entretanto, quitosanas purificadas na forma neutralizada não são solúveis nesse meio. Assim, o sistema solvente mais empregado para a caracterização e a determinação da rigidez/flexibilidade de polieletrólitos polianiônicos através da aplicação do modelo empírico de Smidsrod ${ }^{[4]}$, a solução aquosa de $\mathrm{NaCl}$ de concentração $0,1 \mathrm{~mol} / \mathrm{L}$, não solubiliza quitosana purificada na forma neutralizada. 
No sentido de contribuir para reduzir as citadas dificuldades e para avaliar a conveniência de purificar quitosanas na forma salina para posterior caracterização e comparação com outros polieletrólitos, neste trabalho são descritas e comparadas as metodologias empregadas nas purificações de amostra comercial de quitosana nas formas cloridrato e neutralizada. Graus de acetilação e viscosidades intrínsecas são determinados através de diferentes técnicas e em diferentes meios solventes, de acordo com as características das amostras purificadas. As viscosidades intrínsecas de cloridrato de quitosana em soluções aquosas de $\mathrm{NaCl}$ $0,1 \mathrm{~mol} / \mathrm{L}$ e $0,2 \mathrm{~mol} / \mathrm{L}$ são determinadas com o objetivo de verificar, através da magnitude e da variação da constante de Huggins, a ocorrência de agregação nessas soluções, em ausência de excesso de ácido.

\section{Experimental}

\section{Purificações}

A amostra de quitosana utilizada neste trabalho é um produto comercial (Fluka/BioChemika) que, segundo o fabricante, possui grau de desacetilação de $84,4 \%$ e massa molar média elevada.

A purificação da amostra na forma cloridrato foi realizada por dissolução da amostra comercial em solução de ácido acético diluído, seguida de filtração, diálise e liofilização. A forma neutralizada foi obtida por dissolução, filtração, precipitação, lavagens e secagem da amostra purificada.

Cloridrato de quitosana foi obtido por dissolução da amostra comercial $(1,0 \mathrm{~g}$ de quitosana/100 $\mathrm{mL}$ de ácido acético 1\%) após agitação contínua durante 18 horas. Após este período a solução obtida foi filtrada através de membrana de porosidade $5 \mu \mathrm{m}$. Em seguida foram realizadas diálises com membrana de celofane com limite de exclusão de 12.000 - 14.000 Da por dois períodos consecutivos de 36 horas; o primeiro contra solução aquosa de $\mathrm{NaCl}$ 0,2mol/L e o segundo contra água deionizada. Após as diálises a amostra foi liofilizada e armazenada em dessecador contendo sílica.

Para a obtenção da amostra purificada na forma neutralizada foi adicionado, vagarosamente, 1,0 g de quitosana comercial em $300 \mathrm{~mL}$ de ácido acético (3\%) e a agitação mantida constante por cerca de 18 horas. Após este período a solução obtida foi sequencialmente filtrada através de membranas de porosidades $5,0 \mu \mathrm{m}$, $1,2 \mu \mathrm{m}$ e $0,45 \mu \mathrm{m}$. À solução filtrada foi adicionado
$\mathrm{NH}_{4} \mathrm{OH}$ concentrado para a precipitação da forma neutralizada de quitosana. O precipitado foi filtrado e lavado com $\mathrm{H}_{2} \mathrm{O}$ até a neutralidade e depois com metanol. A amostra purificada foi seca à temperatura ambiente e armazenada em dessecador contendo sílica.

\section{Caracterizações das Amostras}

As amostras purificadas foram caracterizadas através de determinações de teores de umidade e de cinzas, de graus de acetilação (GA) e por viscosimetria capilar de soluções aquosas diluídas.

Os graus de umidade e os teores de cinzas das amostras foram determinados empregando o módulo termogravimétrico DSC 2010 (TGA Instruments), pelo aquecimento, em atmosfera de ar, de cerca de $5-10 \mathrm{mg}$ das amostras à taxa de $10^{\circ} \mathrm{C} / \mathrm{min}$, entre $25^{\circ} \mathrm{C}$ e $700^{\circ} \mathrm{C}$. Para as preparações de soluções de quitosanas utilizadas nas medidas de viscosidade e nas titulações, os graus de umidade das amostras foram levados em consideração para fins de cálculos de concentrações.

\section{Graus de Acetilação}

Os graus de acetilação (GA) das amostras purificadas foram determinados através de espectroscopia ${ }^{1} \mathrm{H}$ nmr e por titulações com solução padronizada de base, acompanhadas por medidas condutimétricas.

Para a execução do primeiro método as amostras foram dispersas em $\mathrm{D}_{2} \mathrm{O}$ para resultar em soluções límpidas de concentração $10 \mathrm{mg} / \mathrm{mL}$ após agitação durante 18 horas. Ao solvente foi adicionado $\mathrm{HCl}$ em quantidade suficiente $\left(\mathrm{D}_{2} \mathrm{O} / \mathrm{HCl} 100: 1 \mathrm{v} / \mathrm{v}\right)$ para promover a solubilização de quitosana (imprescindível para a forma neutralizada de quitosana) e no sentido de deslocar os sinais interferentes da região examinada para a determinação de grau de acetilação. Uma alíquota de aproximadamente $5 \mathrm{~mL}$ da solução de quitosana foi transferida para um tubo apropriado $(\phi=5 \mathrm{~mm})$ e o espectro foi adquirido a $80^{\circ} \mathrm{C}$, utilizando pulso de $90^{\circ}(8,2 \mu \mathrm{S})$ com varredura de $16 \mathrm{NS}$, empregando espectrômetro BRUCKER AC200.

Assim, os graus de acetilação de quitosana foram determinados por espectroscopia ${ }^{1} \mathrm{H}$-rmn através da razão entre as áreas dos prótons metílicos do grupo acetamido $\left(\mathrm{A}_{\mathrm{CH} 3} ; \delta=2,00 \mathrm{ppm}\right)$ e do próton ligado ao carbono 2 do anel de glicosamina $\left(\mathrm{A}_{\mathrm{H} 2} ; \delta=3,12 \mathrm{ppm}\right)$, expressa por ${ }^{[5,6]}$ : 


$$
\% G A=\frac{A_{C H 3}}{3 A_{H 2}} .100
$$

A partir de medidas de condutância da solução de cloridrato de quitosana em água pura a cada volume de base adicionado, a curva de titulação foi construída. Para essas determinações, $0,1 \mathrm{~g}$ de amostra de cloridrato de quitosana foi dissolvido em 80 $\mathrm{mL}$ de água destilada e deionizada, após agitação constante durante cerca de 18 horas. Após este período a solução foi titulada com solução de $\mathrm{NaOH}(0,05$ $\mathrm{mol} / \mathrm{L}$ ) à temperatura de $25^{\circ} \pm 0,1^{\circ} \mathrm{C}$. Foram realizadas duas titulações independentes e nas medidas de condutância foi utilizado condutivímetro CD-21 Digimed.

\section{Viscosidades Intrínsecas}

Para as determinações de viscosidades intrínsecas, [ $\eta$ ], foi utilizado o sistema AVS-350 acoplado a um módulo diluidor automático AVS-20, ambos da Schott-Geräte. As medidas foram realizadas em capilar de vidro $(\phi=0,53 \mathrm{~mm})$ termostatizado em $25^{\circ} \pm$ $0,01^{\circ} \mathrm{C}$ e as soluções foram sequencialmente diluídas no próprio capilar através da adição programada de volumes previamente determinados do solvente adequado. Os valores de tempos de escoamento, empregados para as determinações de $[\eta]$, correspondem a médias de ao menos 5 determinações independentes que não apresentaram variação maior que $0,09 \%$. Todos os tempos de escoamento foram automaticamente corrigidos para efeitos cinéticos pelo acionamento de dispositivo específico no sistema gerenciador das medidas. A amostra purificada como cloridrato de quitosana foi estudada em soluções aquosas de $\mathrm{NaCl} 0,1 \mathrm{~mol} / \mathrm{L}$ e $0,2 \mathrm{~mol} / \mathrm{L}$ e aquela obtida na forma neutralizada em solução aquosa $0,3 \mathrm{~mol} / \mathrm{L}$ ácido acético / 0,2mol/L acetato de sódio $(\mathrm{pH} \cong 4,5)$. Os solventes e as soluções de quitosana empregadas neste estudo foram previamente filtradas através de membranas de porosidade $0,22 \mu \mathrm{m}$.

No tratamento dos dados para determinações de valores de viscosidade intrínseca foi empregada a equação de Huggins ${ }^{[7]}$ : onde:

$$
\eta_{\mathrm{sp}} / \mathrm{C}=[\eta]+\mathrm{k}_{\mathrm{H}}[\eta]^{2} \mathrm{C}
$$

$\eta_{\mathrm{sp}}=$ viscosidade específica; $\mathrm{C}=$ concentração de polímero $(\mathrm{g} / \mathrm{mL}) ;[\eta]$ = viscosidade intrínseca $(\mathrm{mL} / \mathrm{g})$; $\mathrm{k}_{\mathrm{H}}=$ constante de Huggins

\section{Resultados e Discussão}

Amostras uniformes e completamente solúveis de polissacarídeos só são obtidas após um criterioso processo de purificação ${ }^{[3]}$. Quanto à escolha entre as metodologias de purificação devem ser levados em conta o rendimento do processo, a solubilidade e o grau de pureza das amostras purificadas. As purificações de quitosana como cloridrato e na forma neutralizada podem ser realizadas por diferentes metodologias $^{[1,8-10]}$.

O procedimento de purificação empregado neste trabalho para a obtenção de cloridrato de quitosana ocupa muitos dias e resulta em flocos brancos que são fácil e rapidamente dispersos em água e também em soluções aquosas diluídas de ácido acético e de ácido clorídrico. A amostra purificada na forma neutralizada, conforme o procedimento aqui descrito, demanda menos tempo para ser preparada e corresponde a pó, solúvel em soluções aquosas diluídas de ácido clorídrico e de ácido acético mas não em água.

Do ponto de vista de rendimentos, os procedimentos empregados para as purificações da quitosana comercial se assemelham. Ambos resultam entre 70\% e $85 \%$ de material recuperado, sendo que na obtenção de amostras purificadas na forma neutralizada os rendimentos são superiores. Os rendimentos não são muito elevados e são devidos a perdas por manipulação e, principalmente, a materiais insolúveis e agregados excluídos após as etapas de filtrações empregadas nos dois procedimentos. As frações excluídas podem corresponder a cadeias com graus de acetilação superior a $60 \%$ e de massas molares mais elevadas. De fato, a presença de materiais insolúveis nos produtos comerciais tem sido relatada ${ }^{[11]}$ e deve ser atribuída ao fato de tais produtos serem obtidos por desacetilação de quitina em suspensão aquosa alcalina, ou seja, por uma reação heterogênea. Os rendimentos inferiores resultantes da aplicação da metodologia de purificação de quitosana como cloridrato podem ser atribuídos às etapas adicionais de manipulação necessárias à sua execução.

Os dados de graus de umidade (Tabela 1) mostram que a amostra purificada como cloridrato possui grau de umidade muito superior ao da amostra purificada na forma neutralizada. Tal fato deve ser atribuído à maior afinidade por água dos grupos amino protonados comparados com suas formas desprotonadas. Assim, cloridrato de quitosana é um polieletrólito na forma salina com grande afinidade 
Tabela 1. Valores de graus de umidade (GU) e de teores de cinzas residuais (CR) das amostras purificadas de quitosana ${ }^{(a)}$.

\begin{tabular}{ccc}
\hline Amostra & \%GU & \% CR \\
\hline $\mathrm{C}_{\mathrm{N}}$ & 5,10 & 0,00 \\
$\mathrm{C}_{\mathrm{Cl}}$ & 19,00 & 3,40 \\
\hline
\end{tabular}

(a) os subíndices $\mathrm{Cl}$ e $\mathrm{N}$ identificam amostras purificadas como cloridratos e na forma neutralizada, respectivamente.

por água, enquanto que sua forma neutralizada é um polímero descarregado, com menor afinidade por água. O teor residual de cinzas é muito baixo no caso do cloridrato de quitosana e praticamente nulo na forma neutralizada. Um estudo mais amplo demonstrou que ambas as formas purificadas terão teores de cinzas aproximadamente nulos se, nas etapas finais de purificação, as amostras forem exaustivamente lavadas (forma neutralizada) e dialisadas contra água (forma cloridrato $)^{[12]}$. No entanto, as amostras obtidas neste trabalho são de pureza elevada ${ }^{[8]}$ e podem ser usadas em muitas aplicações ${ }^{[9]}$. Deve ser ressaltado que aplicações nas áreas médica e farmacêutica demandam graus ultrapuros ${ }^{[1,2]}$, que podem ser obtidos se cuidados adicionais são tomados ${ }^{[12]}$.

A partir da curva de titulação condutimétrica de cloridrato de quitosana (Figura 1), o ponto de equivalência, correspondente ao ponto de mínima condutância da solução nas vizinhanças da acentuação da inclinação da curva de titulação, pode ser precisamente determinado sem a necessidade de ajustes ou descontos, como deve ser feito no caso da titulação em presença de excesso de ácido ${ }^{[13]}$.

Os valores de graus de acetilação (G.A.) de quitosana comercial purificada em ambas as formas, determinados através de espectroscopia de ressonân-

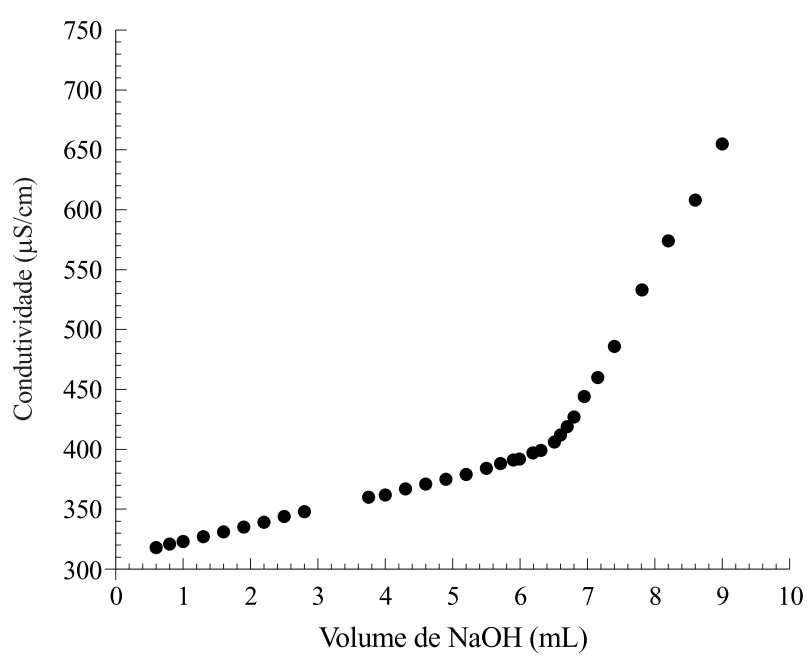

Figura 1. Curva de titulação condutimétrica de cloridrato de quitosana.
Tabela 2. Graus de acetilação de amostras purificadas de quitosanas determinados por espectroscopia ${ }^{1} \mathrm{H}$ rmn, (G.A.) ${ }_{\mathrm{RMN}}$, e por titulação, (G.A) ${ }_{\mathrm{TIT}}$.

Graus de Acetilação

\begin{tabular}{ccc}
\hline Amostra & \%GU & \% CR \\
\hline $\mathrm{C}_{\mathrm{N}}$ & 24,6 & - \\
$\mathrm{C}_{\mathrm{Cl}}$ & 22,7 & 23,0 \\
\hline
\end{tabular}

cia magnética nuclear do próton e por titulação, são mostrados na Tabela 2.

Esses resultados mostram que há boa concordância entre os valores de graus de acetilação da amostra purificada como cloridrato determinados através de titulação e por ${ }^{1} \mathrm{H}$ rmn. Além disso, os valores experimentais de graus de acetilação determinados por ${ }^{1} \mathrm{H}$ rmn das amostras purificadas são concordantes entre si, independentemente da metodologia de purificação empregada, o que indica que ambas as metodologias são adequadas para esse fim. Considerando os graus médios de acetilação de quitosana a partir das determinações por titulação $(\overline{G A}=23,0 \%)$ e por ${ }^{1} \mathrm{H}$ rmn $(\overline{G A}=23,6 \%)$ pode ser constatado que, em comparação com o dado fornecido pelo fabricante $(\overline{G A} \cong 15,6)$, as amostras purificadas apresentam graus de acetilação mais elevados que o produto comercial. Tal diferença não é muito elevada mas sugere que o processo de purificação, com a conseqüente exclusão de materiais insolúveis e agregados, de fato fraciona a amostra de quitosana.

Das curvas de viscosidade reduzida $\left(\eta_{\text {red }}\right)$ versus concentração da solução de quitosana (Figura 2), fo-

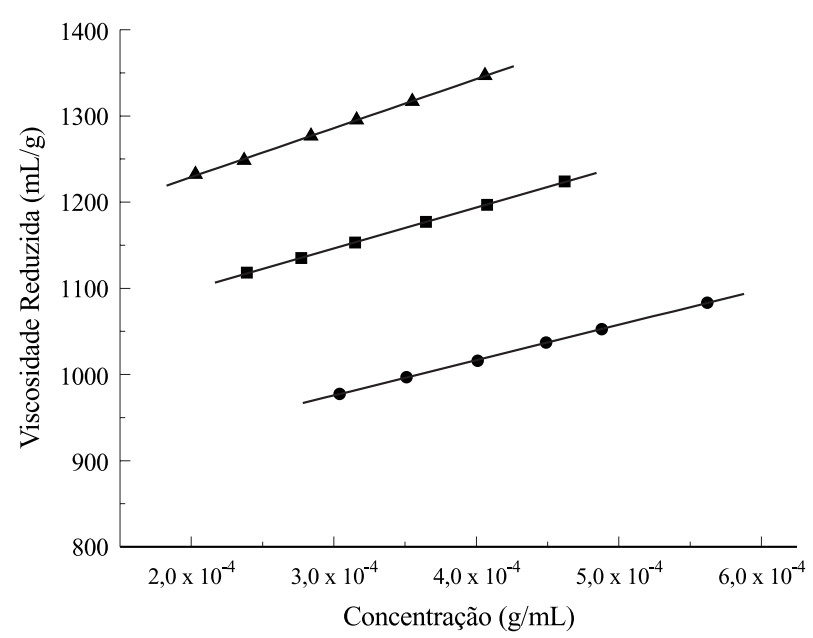

Figura 2. Curvas de viscosidade reduzida versus concentração das amostras de quitosana comercial purificadas como cloridrato $(\mathbb{N a C l}$ 0,1 $\mathrm{mol} / \mathrm{L} ; \bullet \mathrm{NaCl} 0,2 \mathrm{~mol} / \mathrm{L}$ ) e na forma neutralizada ( $\boldsymbol{\Delta}$ ácido acético $0,3 \mathrm{~mol} / \mathrm{L} /$ acetato de sódio $0,2 \mathrm{~mol} / \mathrm{L}$ ). 
Tabela 3. Valores de viscosidade intrínseca, constante de Huggins (valores entre parênteses) e massa molar média viscosimétrica de quitosanas purificadas ${ }^{(a, b)}$.

\begin{tabular}{ccccc}
\hline Amostra & $\begin{array}{c}\left(|\eta|_{\mathrm{NaCl}}\right)^{\mathbf{0 , 1}} \\
(\mathbf{m L} / \mathbf{g})\end{array}$ & $\begin{array}{c}\left(|\eta|_{\mathrm{NaCl}}\right)^{\mathbf{0}, 2} \\
(\mathbf{m L} / \mathbf{g})\end{array}$ & $\begin{array}{c}|\eta|_{\mathrm{AcOH}} \\
(\mathbf{m L} / \mathbf{g})\end{array}$ & $\mathbf{M}_{\mathbf{V}}(\mathbf{g} / \mathbf{m o l})$ \\
\hline $\mathrm{C}_{\mathrm{N}}$ & - & - & $\begin{array}{c}1115 \\
(0,46)\end{array}$ & $315.000^{(\mathrm{a})}$ \\
\multirow{2}{*}{$\mathrm{C}_{\mathrm{Cl}}$} & 1003 & 853 & - & $1.260 .000^{(\mathrm{b})}$ \\
\hline
\end{tabular}

(a)valor calculado empregando $\mathbf{K}=0,074$ e $\mathbf{a}=0,76^{[14]}$; b) valor calculado empregando $\mathbf{K}=1,81 \times 10^{-3}$ e $\mathbf{a}=0,93$ quando o sistema solvente $\mathrm{NaCl}$ $0,2 \mathrm{~mol} / \mathrm{L} /$ ácido acético $0,1 \mathrm{~mol} / \mathrm{L}$ é empregado ${ }^{[5]}$.

ram determinados os valores de viscosidade intrínseca, constante de Huggins e massa molar média viscosimétrica (Tabela 3).

As retas obtidas apresentam excelentes coeficientes de correlação entre os pontos experimentais $(r>0,999)$ e os valores de constantes de Huggins determinados nos solventes estudados são relativamente pequenos (Tabela 3), indicando que soluções de boa qualidade foram obtidas pela dissolução das amostras purificadas de quitosana ${ }^{[14]}$. De fato, os valores de $\mathrm{k}_{\mathrm{H}}$, determinados com cloridrato de quitosana dissolvido em solução aquosa $0,1 \mathrm{~mol} / \mathrm{L}$ de $\mathrm{NaCl}$ e com quitosana purificada na forma neutralizada dissolvida em ácido acético $0,3 \mathrm{~mol} / \mathrm{L}$ /acetato de sódio $0,2 \mathrm{~mol} / \mathrm{L}$, são idênticos e podem ser considerados bons indicativos da solubilidade das amostras em ambos os solventes ${ }^{[14]}$.

Por outro lado, o aumento de $20 \%$ no valor de $\mathrm{k}_{\mathrm{H}}$ determinado em solução aquosa $0,2 \mathrm{~mol} / \mathrm{L}$ de $\mathrm{NaCl}$ sugere que, embora este ainda seja um valor inserido no intervalo considerado normal para soluções poliméricas ${ }^{[15]}$, um processo de agregação passa a ser favorecido à medida que aumenta a concentração de sal externo, como observado com outros polieletrólitos $^{[16,17]}$.

$\mathrm{O}$ valor de viscosidade intrínseca determinado em ácido acético $0,3 \mathrm{~mol} / \mathrm{L} /$ acetato de sódio $0,2 \mathrm{~mol} / \mathrm{L}$ permite, empregando a expressão que relaciona valores de $[\eta]$ e de massas molares médias proposta por Rinaudo et al. ${ }^{[14]}$, determinar $\bar{M}_{\mathrm{V}} \cong 315.000 \mathrm{~g} / \mathrm{mol}$ para a amostra de quitosana purificada na forma neutralizada. A expressão empregada é adequada à determinação de $\bar{M}_{\mathrm{V}}$ pois corresponde a experimentos realizados no mesmo solvente, na mesma temperatura e com amostras purificadas na forma neutralizada através da mesma metodologia. Os parâmetros $\mathrm{K}$ e a usados para o cálculo de $\bar{M}_{\mathrm{V}}$ são confiáveis pois foram obtidos através do tratamento dos dados relativos ao fracionamento de amostras de quitosana em análise de cromatografia de permeação em gel com detecção simultânea de concentração, de viscosidade e de massa molar média ponderal.

O emprego dos parâmetros adotados por Roberts et al. ${ }^{[5]}$ para soluções de quitosana em $\mathrm{NaCl} 0,2 \mathrm{~mol} / \mathrm{L} /$ ácido acético $0,1 \mathrm{~mol} / \mathrm{L}$ resulta em $\bar{M}_{\mathrm{V}} \cong 1.500 .000 \mathrm{~g} /$ mol (Tabela 3) e confirma a informação do fabricante segundo a qual o produto comercial possui massa molar média elevada. Entretanto, segundo alguns autores ${ }^{[14]}$, o valor superestimado resultante da aplicação dos parâmetros descritos por Roberts et al. ${ }^{[5]}$ deve ser atribuído à presença de grandes agregados, presentes como conseqüência da má qualidade termodinâmica do solvente empregado neste último caso.

A utilização dos parâmetros de Roberts et al. ${ }^{[5]}$ leva, portanto, a imprecisões consideráveis devido à ocorrência de agregação que, entretanto, não foi observada quando cloridrato de quitosana foi estudado em soluções aquosas de $\mathrm{NaCl}$ 0,1M e $\mathrm{NaCl}$ 0,2M. Considerando que os solventes empregados no estudo de Roberts et al. ${ }^{[5]}$ e neste trabalho diferem, principalmente, quanto à presença ou não de ácido em excesso, os resultados sugerem que é vantajoso purificar quitosana como cloridrato e estudar a amostra purificada em soluções sem excesso de ácido.

Do estudo do efeito da força iônica sobre as soluções aquosas, sem excesso de ácido, de amostras purificadas de cloridrato de quitosana ${ }^{[12]}$, resultou a determinação da rigidez da cadeia desse polieletrólito através da abordagem de Smidsrod ${ }^{[4]}$. O valor determinado para o parâmetro de rigidez, $\mathrm{B}=0,06$, é muito próximo daquele descrito por Rinaudo et al. ${ }^{[14]}$ mas difere daqueles em que cloridrato de quitosana foi estudado em presença de excesso de ácido ${ }^{[10,18]}$. As discordâncias podem ser decorrentes da agregação de quitosana em solução que ocorre nos dois últimos estudos $\operatorname{citados}^{[19]}$, a qual não foi observada neste estudo e no de Rinaudo et al. ${ }^{[14]}$. De fato, a ocorrência de agregados nas soluções ácidas de quitosana utilizadas por Anthonsen et al. ${ }^{[10]}$ foi observada através de medidas estáticas de espalhamento de luz laser ${ }^{[20]}$.

Os resultados obtidos sugerem que outros estudos (tais como os voltados para caracterizações reológicas, para a construção de curvas $[\eta]=f(M)$, para a determinação de massas molares médias e distribuições de massas moleculares) empregando soluções aquosas de cloridrato de quitosana sem excesso de ácido podem contribuir muito para a caracterização e o estabelecimento de relações estruturas/propriedades de quitosanas. 


\section{Conclusões}

Considerando que o cloridrato de quitosana preparado neste trabalho pode ser estudado em solução aquosa na ausência de ácido e que o valor de $\mathrm{k}_{\mathrm{H}}$ determinado nesse tipo de solvente é característico de soluções de boa qualidade, pode ser concluído que a purificação de quitosana como cloridrato, solúvel em solventes aquosos sem excesso de ácido, da maneira descrita apresenta uma vantagem importante em comparação com a metodologia em que amostras na forma neutralizada são obtidas. Nesse sentido, cloridrato de quitosana tem sido estudado em soluções aquosas sem excesso de ácido e contendo diferentes concentrações de $\mathrm{NaCl}$, possibilitando a determinação da rigidez da cadeia ${ }^{[12,19]}$ que, estimada através da abordagem de Smidsrod ${ }^{[4]}$, é muito próxima daquela de carboximetilcelulose ${ }^{[21]}$, o que é coerente com a interpretação que, ao menos para graus de acetilação relativamente baixos, a rigidez intrínseca da cadeia glicosídica determina a rigidez desses polieletrólitos.

\section{Dedicatória}

Este trabalho é dedicado ao Prof. Dr. Edson Rodrigues, pela ocasião da comemoração de seus 70 anos, pelos inestimáveis serviços prestados em prol da ciência.

\section{Agradecimentos}

Os autores agradecem à FAPESP pelas concessões de recursos nas formas de Auxílio à Pesquisa e de bolsa de Mestrado que viabilizaram a execução deste trabalho.

\section{Referências Bibliográficas}

1. Roberts, G. A. F. - "Chitin Chemistry"; The Macmillan Press Ltd., Londres (1992).

2. Dornish, M.; Hagen, A; Hansson, E.; Pecheur, C.; Verdier, F.; Skaugrud, O - "Advances in Chitin Chemistry", vol.II, p.664; A Domard, G.AF.Roberts; K.M.Varum editors; Jacques Andre Publisher, Lyon/ França (1997).

3. Rinaudo, M.; J. Appl. Polym. Sci.: Appl. Polym. Symp. 52, p.11 (1993).

4. Smidsrod, O; Haug, A.; Biopolymers 10, p.1213 (1971).
5. Roberts, G.A.F.; Domszy, J.G.; Int. J. Biol. Macromol. 4, p.374 (1982).

6. Hirai, A.; Odani, H.; Nakajuma, A. - Polym. Bull. 26, p.87 (1991).

7. Huggins, M. L. - J. Am. Chem. Soc. 64, p.2716 (1942).

8. Struszczyk; M.C.; Loth; F.; Peter, M.G.; in "Advances in Chitin Chemistry" vol.II,. p.71; A Domard, G.AF.Roberts; K.M.Varum editors; Jacques Andre Publisher, Lyon/França (1997).

9. No, H.K.; Meyers, S.P. - “Chitin Handbook”, p.475; Riccardo AA Muzarelli and Martin G. Peter editores; European Chitin Society (1997).

10. Anthonsen, M.W.; Varum, K.M; Smidsrod, O. Carbohydr. Polym. 22, p.193 (1993).

11. Ottoy, M.H.; Varum, K.M.; Smidsrod, O. - Carbohydr. Polym. 29, p.17 (1996).

12. Signini, R. - "Estudos de obtenção, purificação e caracterização de quitosana" Dissertação de Mestrado, Universidade de São Paulo, Brasil (1998).

13. Broussignac, P. - Chim. Ind.: Gen. Chim. 99(9), p.1241 (1968).

14. Rinaudo, M.; Milas, M.; Dung, L.P. - Int. J. Biol. Macromol. 15, 281 (1993).

15. Polymer Handbook "Concentration dependence of the viscosity of dilute polymer solutions: Huggins and Schulz-Blaschke coefficientes"; J. Brandrup \& E.H. Immergut, $3^{\text {rd }}$ edition; VII, p.183; John Wiley \& Sons, USA (1989).

16. Campana Filho, S.P.; Andrade, C.; Milas, M.; Rinaudo, M. - Int. J. Biol. Macromol. 12, p.379 (1990).

17. Rinaudo, M.; Roure, E.; Milas, M. - Int. J. Polym. Anal. Chem. 4(1), p.57 (1998).

18. Tsaih, M.L.; Chen, R.H. - Int. J. Biol. Macromol. 20, 223-240 (1997).

19. Signini, R.; Desbrières, J. Campana Filho, S.P. - "On the stiffness of chitosan hydrochloride"; submetido a Carbohydrate Polymer (1998).

20. Antonsen, M. W.; Varum, K. M.; Hermansson, A N.; Smidsrod, O ; Grant, D. A. - Carbohydr. Polym. 25, pp. 13-23 (1994).

21. Caraschi, J. C.; "Estudos das relações estruturas/propriedades de carboximetilcelulose obtida por derivatização de polpa de bagaço de cana-de-açúcar" Tese de Doutoramento, Universidade de São Paulo (1997).

Recebido: $26 / 03 / 98$ Aprovado: 09/10/98 